\title{
Hereditary renal adysplasia, pulmonary hypoplasia and Mayer-Rokitansky-Küster-Hauser (MRKH) syndrome: a case report
}

\author{
Pedro Acién*1, Francisco Galán², Irene Manchón², Eva Ruiz1 , Maribel Acién and Luis A Alcaraz³
}

\begin{abstract}
Background: Hereditary renal adysplasia is an autosomal dominant trait with incomplete penetrance and variable expression that is usually associated with malformative combinations (including Müllerian anomalies) affecting different mesodermal organs such as the heart, lung, and urogenital system.
\end{abstract}

Case report: A case showing pulmonary hypoplasia, hip dysplasia, hereditary renal adysplasia, and Mayer-RokitanskyKuster-Hauser syndrome in adulthood is reported here. The i.v. pyelography showed right renal agenesis with a normal left kidney and ureter. Ultrasound and Magnetic Resonance Imaging also showed right renal agenesis with multicystic embryonary remnants in the right hemipelvis probably corresponding to a dysgenetic kidney. An uretrocystoscopy showed absence of ectopic ureter and of the right hemitrigone. She was scheduled for a diagnostic laparoscopy and creation of a neovagina according to the McIndoe technique with a prosthesis and skin graft. Laparoscopy confirmed the absence of the uterus. On both sides, an elongated, solid, rudimentary uterine horn could be observed. Both ovaries were also elongated, located high in both abdominal flanks and somewhat dysgenetics. A conventional cytogenetic study revealed a normal female karyotype 46, XX at a level of 550 GTG bands. A CGH analysis was performed using a $244 \mathrm{~K}$ oligoarray CGH detecting 11 copy number variants described as normal variants in the databases. The 17q12 and 22q11.21 microdeletions described in other MRKH patients were not present in this case. Four years after operation her evolution is normal, without symptoms and the neovagina is adequately functional. The geneticists have studied her family history and the pedigree of the family is shown.

Conclusions: We suggest that primary damage to the mesoderm (paraaxil, intermediate, and lateral) caused by mutations in a yet unidentified gene is responsible for: 1) skeletal dysplasia, 2) inappropriate interactions between the bronchial mesoderm and endodermal lung bud as well as between the blastema metanephric and ureteric bud, and eventually 3) Müllerian anomalies (peritoneal mesothelium) at the same level. These anomalies would be transmitted as an autosomal dominant trait with incomplete penetrance and variable expressivity.

\section{Introduction}

According to previous studies [1], unilateral renal agenesis (RA) is embryologically associated with genital and sometimes extragenital malformations. The associated genital malformations are due either to agenesis or hypoplasia of all derivatives of the ipsilateral urogenital ridge (frequently with unicornuate uterus on the opposite side) or to distal mesonephric anomalies [2]. But involution or

\footnotetext{
*Correspondence: acien@umh.es

1 Service of Obstetrics and Gynecology, University Hospital of San Juan; Department of Gynecology, "Miguel Hernández" University, Campus of San Juan, Alicante, Spain

Full list of author information is available at the end of the article
}

secondary renal atrophy without uterine malformation is an alternative embryologic sequence resulting in unilateral RA without Müllerian anomalies. Malformative combinations (including Müllerian anomalies) can sometimes affect different organs derived from the mesoderm, such as the heart, lung, and urogenital system [3]. The MayerRokitansky-Küster-Hauser (MRKH) syndrome is a malformation of the female genitals (occurring in one in 4000 female live births) as a results of interrupted embryonic development of the Müllerian ducts [4]. Strübbe et al. [5] divided their MRKH syndrome patients into two groups: typical (isolated form of congenital agenesis of the vagina and uterus), and atypical form, suggesting to call this last 
type the GRES (genital, renal, ear, skeletal) syndrome. More recently, Oppelt et al. [4] have also classified their 53 cases of MRKH syndrome in three recognized subtypes: typical, atypical and MURCS (Müllerian duct aplasia, renal aplasia, and cervicothoracic somite dysplasia) association. And of the 521 cases included in the revision they do of the literature, $64 \%$ were typical, $24 \%$ atypical and $12 \%$ MURCS. Malformations of the renal system were the most frequent type of accompanying malformation, with 23 different malformations in 19 patients, followed by 19 different skeletal changes in 15 patients of the Oppelt et al's cases. They do not mention cases with pulmonary hypoplasia.

In this communication, we report the case of a patient presenting right hip dysplasia, congenital right pulmonary hypoplasia $(\mathrm{PH})$, and hereditary renal adysplasia with multicystic embryonary remnants in the right hemipelvis (dysgenetic kidney, mesoderm dysplasia) in addition to the Müllerian anomaly known as Rokitansky or MRKH syndrome.

\section{Case Report}

A 17-year-old woman with primary amenorrhea was sent to us with a diagnosis of Rokitansky syndrome. The patient was born via normal delivery at a weight of $2400 \mathrm{~g}$ when her mother was 17 . She was admitted to the hospital at an age of 8 days due to vomiting and moderate dystrophy; she was then diagnosed with primary right $\mathrm{PH}$. She was later readmitted several times for pulmonary insufficiency. Two months later, a diagnosis of congenital right pulmonary hypoplasia with hypoplasia of the right lung artery was confirmed. In an ultrasound examination performed 7 months later, the right kidney was not observed. From more recent (at an age of 15 years) X-ray images taken of the pelvis in the Emergency Unit, the patient was also diagnosed with right hip dysplasia; this condition was initially defined as old secondary osteonecrosis of the right femoral head.

The patient reported three years of genital and mammary development as well as cyclic pelvic pain for 4-5 days every month despite the primary amenorrhea. She weighed $42 \mathrm{~kg}$ and was $153 \mathrm{~cm}$ tall. The physical examination revealed normal external genital development and normal breasts. There was complete vaginal atresia. In the combined rectal examination, the pelvis was noted to be free. A transrectal ultrasound did not confirm the presence of a uterus. In this ultrasound examination, there was difficulty visualizing the ovaries; on the right side, however, vascular dilatations or multicystic embryonary remnants could be observed. The abdominal ultrasound did not show the presence of a right kidney. General and hormonal analyses were normal (FSH 3.9 $\mathrm{mUI} / \mathrm{mL}, \mathrm{LH} 6.2 \mathrm{mUI} / \mathrm{mL}$, PRL $7.9 \mathrm{ng} / \mathrm{mL}$, E2 35 pg/mL, P $0.3 \mathrm{ng} / \mathrm{mL}$ ), and chest X-rays and i.v. pyelography showed right pulmonary hypoplasia, dysplasia of the right hip, and right renal agenesis with a normal left kidney and ureter (see Figure 1). Later, a conventional cytogenetic study revealed a normal female karyotype 46, XX at a level of 550 GTG bands. A CGH analysis was performed using a $244 \mathrm{~K}$ oligoarray CGH (Agilent Technologies, Santa Clara, CA, USA), detecting 11 copy number variants $(\mathrm{CNV})$ described as normal variants in the databases. Some CNVs (17q12 and 22q11.21 microdeletions) described in other MRKH patients were not present in this case. The geneticists have been studying her family history and Figure 2 shows the pedigree of the family, compatible with an autosomal dominant pattern of inheritance.

Eight months later, a new transrectal ultrasound was performed. Again, there was no evidence to suggest any functioning rudimentary uterine horn. The right ovary appeared to be normal, and there were the same vascular dilatations or multicystic remnants previously seen on the right side. The left ovary was also difficult to identify properly. The patient, who visited the clinic with her parents, wished operation and to have a neovagina created. She was therefore scheduled for a diagnostic laparoscopy and creation of a neovagina according to the McIndoe technique with a prosthesis and skin graft.

Laparoscopy confirmed the absence of uterus. There was a varicocele and/or retroperitoneal multicystic formations on the right side of the small pelvis. On both sides, an elongated, solid, rudimentary uterine horn could be observed. At its superior end, there were ovaries that



Figure 1 A. Antero-posterior X-ray of the thorax showing right pulmonary hypoplasia. Ascent of the diaphragm (>) and displacement of the heart to the right. B. I.V. pyelography showing right renal agenesis (or dysplasia) (>). The right hip dysplasia is also shown (>>). C. Transrectal ultrasound image of the supposed right ureterocele. D. Laparoscopic images of both ovaries (RO, right ovary; LO, left ovary). 




were elongated, somewhat dysgenetic (more on the right side), and located very high in both abdominal flanks (Figure 1D). Rudimentary tubes could also be observed. Although the uterine rudimentary tract was slightly thicker on the left side, there did not appear to be even minimal endometrial cavitation of the solid uterine rudimentary horn. Sectioning and dissection from the introitum to the inside below the urethra was performed via a transperineal procedure, thus forming a wide vaginal neocavity reaching the Douglas pouch. Interestingly, the dissection of the neovaginal cavity tended more toward the left fundus than the right, as if there were more atresia on the right side of the supposed location of the vagina. A prosthesis with a skin graft taken from the right buttock was applied, with Interceed ${ }^{\circ}$ placed between the skin and the prosthesis (Figure 3). The drawing of the genital tract of the patient generated in the surgery theater is shown in Figure 2B. After 10 days, the prosthesis was removed and the state of the neovagina was assessed. After replacement of the prosthesis, the patient was discharged. The patient returned for a follow-up visit 6 months after the operation, and her evolution was normal. She then underwent transvaginal ultrasound that did not show the ovaries properly but showed the multicystic embryonary remnants in the right hemipelvis. An uretrocystoscopy showed absence of ectopic ureter and of the right hemitrigone. Likewise, the Magnetic Resonance Imaging (MR) showed right renal agenesis with probable



Figure $3 \mathrm{~A}$. Vulva and vestibule showing the vaginal agenesis. $B$. Drawing (diagram) of the genito-urinary anomaly of the patient (RRA, right renal agenesis; $\mathrm{RO}$, right ovary; $L O$, left ovary; $R R U H$, right rudimentary uterine horn; LRUH, left rudimentary uterine horn). C. Surgical dissection and formation of the neovaginal cavity (>). D. Prosthesis with skin graft placed in situ. E. Observation of the epidermization of the neovagina 10 days after surgery.

embryonary remnants of a disgenetic kidney in the right hemipelvis with a multicystic morphology (see Figure 4). Those cysts seem to have slightly increased in the transvaginal ultrasound, but four years after operation her evolution is normal, without symptoms and the neovagina is adequately functional.

\section{Discussion}

Renal agenesis and dysplasia (both unilateral and bilateral) are frequently observed in fetuses and newborns,

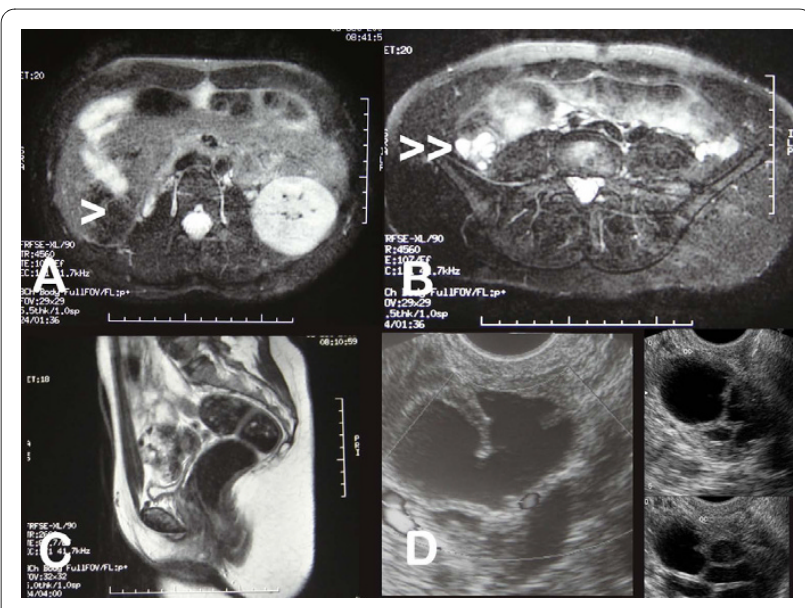

Figure $4 \mathrm{~A}$ and $\mathrm{B}$ : Magnetic Resonance Imaging showing the right renal agenesis ( $>$ ) and the multicystic embryonary remnants in the right hemipelvis (>>). C. Medial cut in the axial plane. Absence of the uterus. D, Multicystic images in the right hemipelvis (probably a dysgenetic kidney) by transvaginal ultrasound four years after operation. 
and have been commonly considered by pathologists and pediatricians to be sporadic malformations. However, hereditary renal adysplasia is an autosomal dominant trait with incomplete penetrance and variable expression [6-8]. It can be associated with other heart, lung, or genital anomalies. Its penetrance is between $50 \%$ and $90 \%$, and ultrasound study of the kidneys of parents, siblings, and other relatives is recommended in all families with unilateral or bilateral RA individuals [7].

Pulmonary hypoplasia (PH) consists of the presence of variable amounts of pulmonary primordium, bronchial tree, and supporting vasculature. Bilateral $\mathrm{PH}$ is a major cause of neonatal mortality and morbidity [9]. Unilateral $\mathrm{PH}$ is a defect compatible with an almost normal existence though, and its associated defects govern the prognosis of the patients. Unilateral lung malformation is frequently associated with other singular or complex anomalies (e.g. renal and vascular) [10].

Mirapeix et al [11] noted that the association between bilateral RA and bilateral PH is well known, but that unilateral agenesis of both organs is rare, despite the fact that five cases had been observed in neonatal and infant necropsies. As an unusual association present in adulthood, a case was reported of left RA and left PH in a 46year-old woman. These concurrent deformities suggested interference with embryologic development, and the morphogenesis of both structures (i.e., the lungs and kidneys) was suggested to have three points in common: 1 ) they require the induction of the mesoderm on the bronchial and ureteric buds [11,12];2) they develop during the same period [13]; 3) for normal lung development, the presence of a pulmonary growth factor produced by the kidney is required $[14,15]$. However, the relationship of the developing lung and kidney is not completely understood. Renal enlargement has been reported in association with pulmonary hypoplasia in congenital diaphragmatic hernia [16].

As we pointed out in the introduction, unilateral RA (and its associated genital anomalies) generally arises due to either: a) agenesis or hypoplasia of a urogenital ridge or b) distal mesonephric anomalies with early degeneration or absence of the ureteric bud that result in a lack of induction of the metanephric blastema $[17,18]$. The lung bud appears in the $4^{\text {th }}$ week of fetal life as a median laryngo-tracheal groove in the ventral wall of the foregut [19]; by the $5^{\text {th }}$ week, the lung bud starts branching [13]. This process requires an interaction between the specific bronchial mesoderm and the bud endoderm [12]. Moreover, for normal early lung growth, several investigators [20] have suggested that the presence of the kidney is important.

Mirapeix et al [11] also noted that the simultaneous occurrence of both malformations (RA and $\mathrm{PH}$ ) might be the result of 1) the simultaneous action of two or more teratogens, 2) the presence of one malformation (RA) that induces the other $(\mathrm{PH})$, or 3) the presence of one teratogen that damages several developmental processes during the $5^{\text {th }}$ week. These mechanisms agree with Källen and Winberg's hypothesis [21] that variable cranio-caudal extension of primary damage in the mesoderm could explain the different manifestations of Potter's syndrome as well as associated anomalies.

Müllerian aplasia (Rokitansky or MRKH syndrome) has been defined as an absent or rudimentary uterus and upper vagina in 46 , XX females with normal secondary sexual development. As pointed out above, more than $30 \%$ of these women have associated defects, with renal and skeletal anomalies occurring most frequently. Although most cases are isolated, familial cases with autosomal dominant transmission, incomplete penetrance, and variable expressivity account for more than $20 \%$ of cases. Some candidate genes and chromosome regions (e.g., HOXA7-13, PBX1, EMX2, PAX2, WT1, $10 \mathrm{q} 26$, and 6p) have been studied [22,23]; however, clear associations have not yet been established. Recently, an array-based comparative genomic hybridization study detected molecular imbalances, including 22q11.21, 17q12, and Xq21.31 deletions and a 1q21.1 duplication [24]. Other two MRKH patients described recently [25] carry the same $1.5 \mathrm{Mb}$ de novo $17 \mathrm{q} 12$ microdeletion, including TCF2 and LHX1 genes. The other $20 \mathrm{MRKH}$ patients in this study, as in our case, do not carry the microdeletion and sequencing of TCF2 and LHX1 genes does not detect pathological mutations. All these data suggest a wide genetic heterogeneity for MRKH syndrome.

Therefore, it is possible that primary damage to the mesoderm (paraaxil: muscle, skeletal; intermediate: urogenital; lateral: lung, heart, and serosal membranes) originates from: 1) inadequate interaction between the bronchial mesoderm and endodermal lung bud; 2) inadequate interaction between the metanephric blastema and ureteric bud (which, rather than pulmonary or renal agenesis, would then cause hypoplasia and dysgenetic kidney); 3) eventual Müllerian anomalies at that same level. It is important to remember that the Müllerian or paramesonephric ducts are formed from longitudinal invaginations of the mesothelium on the lateral face of the urogenital ridge and mesonephros. Such mesothelial tissues (specifically, the serous membranes of the pleura, pericardium, and peritoneum) are derived from the lateral mesoderm [3]. In this case, our patient also presented dysplasia of the right hip (skeletal dysplasia), which likewise suggested damage to the paraaxil mesoderm.

Mirapeix et al. [11] did not describe the genitals of the 46-year-old woman they studied with pulmonary hyp- 
oplasia and RA, and the genital tracts in other cases with neonatal death (almost always with family antecedents of RA) were not described either [26,27]. However, Schimke et al. [28] previously reported a family in which threegeneration transmission of renal agenesis-dysplasia occurred with no skeletal defects but with uterine anomalies. Pavanello et al. [29] also reported a relationship between Rokitansky syndrome and hereditary renal adysplasia. Likewise, Battin et al. [30] reported a family with unilateral or bilateral RA and Müllerian anomalies. Strubbe et al. [5] studied 100 cases with MRKH syndrome and, as we said before, divided the patients into two groups (i.e., a typical and atypical form) suggesting that this type of MRKH syndrome should be called GRES (genital, renal, ear, skeletal) syndrome. Carranza-Lira et al. [31] also described three patients with MRKH syndrome and a MURCS (Müllerian renal cervical somite) association. Finally, Morcel et al. [32] also described that MRKH may be isolated (type I) but it is more frequently associated with renal, vertebral, and, to a lesser extent, auditory and cardiac defects (MRKH type II or MURCS association). The etiology still remains unclear.

Nonetheless, simultaneous pulmonary hypoplasia, renal agenesis or dysplasia, and MRKH syndrome have not been observed in adulthood; further, our case also presented hip dysplasia. The multicystic embryonary remnants in the right hemipelvis suggest a dysgenetic kidney and secondary involution rather than an actual RA due to agenesis of the urogenital ridge on one side or distal mesonephric anomaly.

\section{Conclusions}

We suggest that primary damage to the mesoderm (paraaxil, intermediate, and lateral) caused by mutations in a yet unidentified gene is responsible for skeletal, pulmonary, renal, and for Müllerian dysplasias present in MRKH syndrome and usually transmitted as an autosomal dominant trait with incomplete penetrance and variable expressivity.

\section{Consent}

Written informed consent was obtained from the patient for publication of this case report and accompanying images. A copy of the written consent is available for review by the Editor-in-Chief of this Journal.

\section{Competing interests}

The authors declare that they have no competing interests.

\section{Authors' contributions}

PA and ER were the gynecologist that operated and followed the patient. PA conceived the study and participated in its design and coordination and wrote the draft of the manuscript. MA participated in the design of the study and reviewed the literature. FG and IM made the genetic studies, studied the family history and carried out the pedigree of the family. LAA performed the oligoarray $\mathrm{CGH}$ analysis. All authors have contributed equally to this study. All authors read and approved the final manuscript.
PA had full access to all of the data in the study and takes responsibility for the integrity of the data and the accuracy of the data analysis.

\section{Acknowledgements}

To Noemi Acién and American Journal Experts for editing and reviewing the English.

\section{Author Details}

'Service of Obstetrics and Gynecology, University Hospital of San Juan; Department of Gynecology, "Miguel Hernández" University, Campus of San Juan, Alicante, Spain, ${ }^{2}$ Centro de Genética Humana. Alicante, Spain and

${ }^{3}$ Bioarray S.L., Alicante, Spain

Received: 7 December 2009 Accepted: 14 April 2010

Published: 14 April 2010

\section{References}

1. Acién $P, A c i e ́ n$ M: Malformations of the female genital tract and embryological bases. Curr Women's Health Rev 2007, 3:248-288.

2. Acién $P$, Acién M, Sánchez-Ferrer M: Complex malformations of the female genital tract. New types and revision of classification. Hum Reprod 2004, 19:2377-84.

3. Moore KL, Persaud TVN: The developing human. Clinically oriented embryology. Fifth edition. W.B. Saunders Company; 1993.

4. Oppelt P, Renner SP, Kellermann A, Brucker S, Hauser GA, Ludwig KS, Strissel PL, Strick R, Wallwiener D, Beckmann MW: Clinical aspects of Mayer-Rokitansky-Küster-Hauser syndrome: recommendations for clinical diagnosis and staging. Hum Reprod 2006, 21:792-97.

5. Strübbe EH, Cremers CW, Willemsen WN, Rolland R, Thijn CJ: The MayerRokitansky-Küster-Hauser (MRKH) syndrome without and with associated features: two separate entities? Clin Dysmorphol 1994, 3:192-9.

6. Buchta RM, Viseskul C, Gilbert EF, Sarto GE, Opitz JM: Familiar bilateral renal agenesis and hereditary renal adysplasia. Z Kinderheilkd 1973, 115:111-29.

7. McPherson E, Carey J, Kramer A, Hall JG, Pauli RM, Schimke RN, Tasin MH: Dominantly inherited renal adysplasia. Am J Med Genet 1987, 26:863-72.

8. Dursun A, Ermis B, Numanoglu V, Bahadir B, Seckiner I: Bilateral multicystic renal dysplasia with potter sequence. A case with penile agenesis. Saudi Med J 2006, 27:1745-7.

9. Nicolini U, Fisk NM, Rodeck CH, Talbert DG, Wigglesworth JS: Low amniotic pressure in oligohydramnios is this the cause of pulmonary hypoplasia? Am J Obstet Gynecol 1989, 161:1098-1101.

10. Dembinski J, Kroll M, Lewin M, Winkler P: Unilateral pulmonary agenesis, aplasia and dysplasia. Z Geburtshilfe Neonatol 2009, 213:56-61.

11. Mirapeix RM, Domingo Ch, Sañudo JR, Mata JM: Unusual association of two unilateral anomalies present in adulthood: pulmonary hypoplasia and renal agenesis. Embryology and clinical expression. Surg Radiol Anat 1995, 17:177-179.

12. Spooner BS, Wessels NK: Mammalian lung development: interactions in primordium formation and bronquial morphogenesis. J Exp Zool 1970, 175:445-454

13. Maloney JE, Alcorn D, Bowes G, Wilkinson M: Development of the future respiratory system before birth. Semin Perinatol 1980, 4:251-60.

14. Glick PL, Siebert JR, Benjamin DR: Pathophysiology of congenital diaphragmatic hernia: I. Renal enlargement suggests feedback modulation by pulmonary derived renotropins-A unifying hypothesis to explain pulmonary hypoplasia, polyhydramnios, and renal enlargement in fetus/newborn with congenital diaphragmatic hernia. J Pediatr Surg 1990, 25:492-495.

15. Hosoda Y, Rossman JE, Glick PL: Pathophysiology of congenital diaphragmatic hernia. IV: Renal hyperplasia is associated with pulmonary hypoplasia. J Pediatr Surg 1993, 28:464-9.

16. Montedonico S, Nakazawa N, Shinkai T, Bannigan J, Puri P: Kidney development in the nitrofen-induced pulmonary hypoplasia and congenital diaphragmatic hernia in rats. J Pediatr Surg 2007, 42:239-43.

17. Acién P: Embryological observations on the female genital tract. Hum Reprod 1992, 7:437-45.

18. Sánchez-Ferrer M, Acién MI, Sánchez del Campo F, Mayol-Belda MJ, Acién $P$ : Experimental contributions to the study of the embryology of the vagina. Hum Reprod 2006, 21:1623-28. 
19. Sañudo JR, Domenech-Mateu JM: The laryngeal primordium. A new explanation. J Anat 1990, 175:207-222.

20. Petters GA, Reid LM, Docimo S, Luetic T, Carr M, Retik AB, Mandell J: Role of the kidney in lung growth and maturation in the setting of obstructive uropathy and oligohydramnios. J Urol 1991, 146:597-600.

21. Källen B, Winberg J: Caudal mesoderm pattern of anomalies: from renal agenesis to sirenomelia. Teratology 1974, 9:99-112.

22. Guerrier D, Mouchel Th, Pasquier L, Pellerin I: The Mayer-RokitanskyKüster-Hauser syndrome (congenital absence of uterus and vagina)phenotypic manifestations and genetic approaches. J Negat Results Biomed 2006, 5:1.

23. Moerman P, Fryns JP, Sastrowijoto SH, Vandenberghe K, Lauweryns JM: Hereditary renal adysplasia: new observations and hypothesis. Pediatr Pathol 1994, 14:405-10.

24. Cheroki C, Krepischi-Santos ACV, Szuhai K, Brenner V, Kim CA, Otto PA, Rosemberg C: Genomic imbalances associated with müllerian aplasia. J Med Genet 2008, 45:228-232.

25. Bernardini L, Gimelli S, Gervasini C, Carella M, Baban A, Frontino G, Barbano G, Divizia MT, Fedele L, Novelli A, Bèna F, Lalatta F, Miozzo M, Dallapiccola B: Recurrent microdeletion at $17 q 12$ as a cause of MayerRokitansky-Kuster-Hauser (MRKH) syndrome: two case reports. Orphanet J Rare Dis 2009, 4(1):25.

26. Doray B, Gasser B, Reinartz I, Stoll C: Hereditary renal adysplasia in a three generations family. Genet Couns 1999, 10:251-7.

27. Morava E, Smith C, Pierce M, Andersson HC: Management dilemmas in patients with hereditary renal adysplasia. J La State Med Soc 2001, 153:27-30.

28. Schimke RN, King CR: Hereditery urogenital adysplasia. Clin Genet 1980, 18:417-20.

29. Pavanello R, de C, Eigier A, Otto PA: Relationship between MayerRokitansky-Kuster (MRK) anomaly and hereditary renal adysplasia (HRA). Am J Med Genet 1988, 29:845-9.

30. Battin J, Lacombe D, Leng JJ: Familiar occurrence of hereditary renal adysplasia with müllerian anomalies. Clin Genet 1993, 43:23-4.

31. Carranza-Lira S, Forbin K, Martinez-Chéquer JC: Rokitansky syndrome and MURCS association-clinical features and basis for diagnosis. Int $\mathrm{J}$ Fertil Womens Med 1999, 44:250-5.

32. Morcel K, Camborieux L, Programme de Recherches sur les Aplasies Müllèriennes, Gerrier D: Mayer-Rokitansky-Küster-Hauser (MRKH) syndrome. Orphanet J Rare Dis 2007, 2:13.

\section{doi: 10.1186/1750-1172-5-6}

Cite this article as: Acién et al., Hereditary renal adysplasia, pulmonary hypoplasia and Mayer-Rokitansky-Küster-Hauser (MRKH) syndrome: a case report Orphanet Journal of Rare Diseases 2010, 5:6

\section{Submit your next manuscript to BioMed Centra and take full advantage of:}

- Convenient online submission

- Thorough peer review

- No space constraints or color figure charges

- Immediate publication on acceptance

- Inclusion in PubMed, CAS, Scopus and Google Scholar

- Research which is freely available for redistribution

Submit your manuscript at www.biomedcentral.com/submit
C Biomed Central 